\section{G76 WORKING TOGETHER TO IMPROVE THE CARE OF YOUNG PEOPLE WITH MENTAL HEALTH PROBLEMS IN HOSPITAL}

${ }^{1} \mathrm{~K}$ Certic, ${ }^{2} \mathrm{~J}$ Waine, ${ }^{3} \mathrm{~S}$ Dhakras, ${ }^{4} \mathrm{~K}$ Pryde. ${ }^{1}$ Paediatrics Department, Portsmouth Hospitals NHS Trust, Portsmouth, UK; ${ }^{2}$ Child and Adolescent Mental Health Services, University Hospital Southampton NHS Foundation Trust, Southampton, UK; ${ }^{3}$ Child and Adolescent Mental Health Services, Solent NHS Trust, Southampton, UK; ${ }^{4}$ Paediatrics Department, University Hospital Southampton NHS Foundation Trust, Southampton, UK

\subsection{6/archdischild-2018-rcpch.74}

Aims To reduce variability in the management of young people with mental health problems in hospital by improving communication and joint working between Paediatrics, Child and Adolescent Mental Health Services (CAMHS) and Emergency Medicine (EM) teams within our region.

Method In order to identify the problems affecting the management of young people with mental health problems in hospital, a series of meetings was held with doctors, nursing staff and allied health professionals from the Paediatrics, CAMHS and EM teams in two hospitals in our region. 17 different issues were raised at these meetings. Using a structured questionnaire, teams identified the three most important of these to be: 1. Management of young people with acute behavioural disturbance; 2. Poor communication between teams; and 3 . Insufficient training of hospital staff. Three interventions were then developed to address these problems. First, multidisciplinary team debriefs were introduced at each hospital, providing all three teams with an opportunity to discuss challenging cases. Second, an interprofessional study day on the management of acute behavioural disturbance was developed and delivered by members of the CAMHS, Paediatrics and EM teams. Third, a group of Paediatric nurses visited the local CAMHS inpatient unit to discuss nursing issues with the specialist CAMHS nursing team.

Results Feedback from debriefs was universally positive, and they will now run six-monthly at each hospital. The study day has run twice, with a total of 75 attendees. Pre- and post-course feedback forms showed a marked improvement in confidence managing acute behavioural disturbance across all staff groups attending. This course will now run three times per year. Additionally, all those who visited the inpatient unit reported that it would lead to a positive change in their practice.

Conclusion These efforts to bring teams together have been highly valued by all involved, and we are receiving ongoing support from our deanery to continue this work. Several further joint-working initiatives are now being developed within our region as a result of this project, showing the positive and far-reaching repercussions of these relatively simple interventions.

\section{G77(P) SOCIOECONOMIC AND MATERNAL REPRODUCTIVE FACTORS AFFECTING LOW BIRTH WEIGHT BABIES IN CENTRAL NEPAL}

${ }^{1} \mathrm{M}$ Shrestha, ${ }^{1}$ SK Gupta, ${ }^{1}$ BK Sarmah, ${ }^{2} \mathrm{M}$ Baidya. ${ }^{1}$ Pediatrics, College of Medical Sciences, Chitwan, Nepal; ${ }^{2}$ Kathmandu University, Dhulikhel, Nepal

\subsection{6/archdischild-2018-rcpch.75}

Introduction Low Birth weight is one of the most sensitive and reliable predictors of health and also an essential determinant of mortality, morbidity and disability in infancy and childhood. Globally, about one sixth of all newborns are low birth weight $(\mathrm{LBW}<2500$ grams), which is the single most important underlying risk factors for neonatal deaths. It is estimated that 18 million babies are born with Low Birth Weight and half of them are born in south Asia. Over three quarters of newborns death in Nepal occur in LBW babies. The estimates of prevalence of LBW in Nepal have ranged from $14 \%$ in community based studies to $32 \%$ in hospital based ones, overall being $27 \%$. Objectives were to study the various socioeconomic and maternal reproductive factors related to low birth weight babies in Central regional part of Nepal.

Material and Methods Cross-sectional and observational study was undertaken from October 2012 to September 2014 comprising of 350 singleton live born baby admitted in NICU of Tertiary Care Teaching Hospital, Chitwan.

Results The common risks factors for LBW were significantly associated with low socio- economic status, maternal age, maternal education, occupation of mother, maternal smoking, maternal alcohol intake, number of ANC visit with significant p-value of $<0.05$.

Conclusion LBW mostly associated with maternal factors can be addressed directly by improving the socioeconomic factors (maternal age, educational level and economic status) and health status of pregnant women by supplementations, family planning services and female education.

\section{G78(P) FACTORS AFFECTING BOLUS IV FLUID PRESCRIPTIONS IN PAEDIATRICS}

${ }^{1}$ G Allport, ${ }^{2}$ S Playfor. 'University of Manchester Medical School, Manchester University, Manchester, UK; ${ }^{2}$ Paediatric Intensive Care Unit, Royal Manchester Children's Hospital, Manchester, UK

\subsection{6/archdischild-2018-repch.76}

Aims Bolus administration of $0.9 \%$ sodium chloride solution has been associated with hyperchloraemia, acidosis, acute kidney injury and increased mortality. Such adverse effects are believed to be less likely with balanced electrolyte solutions, such as Plasma-Lyte 148. Despite this, 0.9\% sodium chloride solution remains a popular choice for intravenous fluid boluses in paediatrics. This project aims to establish current practice and to collect testimony from prescribers to help understand why decisions to prescribe specific fluids were made.

Method Paediatric patients in critical care areas (PICU and PHDU), the Emergency Department (PED) and in general ward areas who had been administered intravenous fluid boluses were identified using a pragmatic data collection technique and the dose, type of fluid, indication and patient's weight were recorded. Where possible, the prescriber was identified and asked to be interviewed. Prescribers were asked what factors had affected their decision to prescribe the type and dose of fluid administered.

Results More than 30 individual episodes of intravenous fluid bolus administration were identified. Most fluid boluses were administered in PICU and PHDU, where balanced electrolyte solutions, specifically Plasma-Lyte 148, were the most popular choice. On general wards and in PED, 0.9\% sodium chloride solution remained the most commonly administered fluid bolus solution. While some prescribers were able to give confident explanations of the factors involved in fluid selection, others referred to clinical guidelines. Individual prescribers described how their prescribing practice would vary according 